\title{
BMJ Open Factors influencing self-concept among adolescents infected with HIV: a cross- sectional survey in China
}

\author{
Siyuan Ke, ${ }^{1}$ Yanjie Yang, ${ }^{1}$ Xiuxian Yang, ${ }^{1}$ Xiaohui Qiu, ${ }^{1}$ Zhengxue Qiao, ${ }^{1}$ \\ Xuejia Song, ${ }^{1}$ Erying Zhao, ${ }^{1}$ Wenbo Wang, ${ }^{1}$ Jiawei Zhou, ${ }^{1}$ Yuewu Cheng ${ }^{2}$
}

To cite: Ke S, Yang Y, Yang $\mathrm{X}$, et al. Factors influencing self-concept among adolescents infected with HIV: a cross-sectional survey in China. BMJ Open 2020;10:e022321. doi:10.1136/ bmjopen-2018-022321

- Prepublication history for this paper is available online. To view these files, please visit the journal online (http://dx.doi.org/ 10.1136bmjopen-2018-022321)

Received 16 February 2018 Revised 05 October 2019 Accepted 14 October 2019
Check for updates

(C) Author(s) (or their employer(s)) 2020. Re-use permitted under CC BY-NC. No commercial re-use. See rights and permissions. Published by BMJ.

${ }^{1}$ Medical Psychology Department, Public Health School of Harbin Medical University, Harbin, Heilongjiang, China

${ }^{2}$ Shangcai Center for Disease Control and Prevention, Zhumadian, Henan, China

Correspondence to Professor Yanjie Yang; yanjie1965@163.com

\section{ABSTRACT}

Overview The mental health problems of adolescents with human immunodeficiency virus (HIV) are important. It is of great significance to explore which factors can affect the self-evaluation and understanding of adolescents with HIV.

Objective We found that adolescents with HIV have a lower level of self-concept than healthy adolescents. This study aimed to determine the factors influencing selfconcept among adolescents with HIV in China.

Setting A questionnaire was distributed among a total of 290 adolescents in Henan Province, China. One hundred and forty questionnaires were distributed in the case group (adolescents with HIV) and the control group (healthy adolescents) was issued 150 questionnaires. The Piers-Harris Children's Self-concept Scale, the Perceived Stress Scale, the Perceived Social Support Scale and the Simplified Coping Style Questionnaire were adapted for a Chinese population. Differences between the groups were tested for significance using Student's t-test, and analysis of variance was used to test continuous variables. The relationship between environmental personality factors and adolescent self-concept was examined by Pearson correlation analysis. Hierarchical linear regression analysis was used to model the effects of environmental personality factors on self-concept.

Results The self-concept total score among adolescents with HIV was significantly lower than healthy adolescents $(p<0.05)$. Hierarchical regression analysis indicated that age $(\beta=-0.19, t=-2.16, p=0.03)$, perceived stress $(\beta=-0.19, t=-2.22, p=0.03)$, perceived social support $(\beta=0.26, t=3.25, p=0.00)$, positive coping style $(\beta=0.50$, $t=5.75, p=0.00)$ and negative coping style $(\beta=-0.45$, $\mathrm{t}=-5.33, \mathrm{p}=0.00$ ) were significantly associated with selfconcept total scores.

Conclusions The self-concept of adolescents with HIV is related to perceived stress, perceived social support and coping style. These findings underline the significance of self-concept among adolescents infected with HIV.

\section{INTRODUCTION}

Over the years, AIDS has spread throughout the world at an extremely rapid rate. In 1985, AIDS began to spread in a few African countries. By 2005, AIDS had affected nearly all countries and regions worldwide. ${ }^{1}$ As a result of AIDS, the mortality rate of the adult

\section{Strengths and limitations of this study}

This is the first study to determine the factors influencing self-concept among adolescents with HIV in China.

- Although adolescents with HIV are a special group, the sample size was suitably powered to allow statistical analysis including hierarchical linear regression.

- This was a cross-sectional study and thus causal relationships between the self-concept of adolescents with HIV and influencing factors require further exploration.

population has increased significantly. ${ }^{2} \mathrm{HIV}$ is spread through exposure to HIV-infected blood or other body fluids. The primary transmission modes include contact with an infected person's body fluids during unprotected sex, blood-to-blood exposure (either by direct contact or through needle sharing among injection drug users) and perinatal transmission from infected mother to child. The main target of mother-to-child transmission of AIDS is children and adolescents and the inevitable consequence is that a large number of adolescents lose their parents because of AIDS. The typical socioeconomic status of families and individuals in communities with a high incidence of AIDS means that those adolescents who have acquired AIDS through mother-to-child transmission have a visible vulnerability in terms of physical, psychological and social adaptation. ${ }^{3}$ At present, the number of adolescents with HIV in China is large and rapidly increasing. Living conditions, social environment and mental health difficulties are serious problems that have had an enormous impact on the growth and development of adolescents with HIV. The study of Qian and Wang in China in 2007 reported that prejudice and discrimination have a substantial negative impact on the health of adolescents with HIV. ${ }^{4}$ The mental 
health difficulties experienced by the children who lost their parents to HIV/AIDS are mainly due to a decrease in self-concept and an increase in depression. ${ }^{5-7}$ All the difficulties described above impact on self-concept among adolescents with HIV, and we predict that self-concept in adolescents with HIV is lower than in healthy adolescents.

Self-concept is a cognitive assessment of one's own abilities and weaknesses ${ }^{8}$ and plays an important role in mental health. Low levels of self-concept are a risk factor of mental health problems. High levels of self-concept are considered to be a protective factor that hinders the development of psychological problems and promotes general health. ${ }^{9-12}$ Harter proposed a multidimensional model of self-concept from the perspective of developmental psychology and believed that adolescence was a critical period for the development of self-concept. ${ }^{13}$ An individual's perception of himself/herself changes significantly during adolescence, or even undergoes a dramatic reversal. ${ }^{14}$ In the early stages of puberty, adolescents are more likely to compare themselves with others, and to consider how they are perceived and judged by others. Adolescents also begin to give higher value to these judgements. ${ }^{15}$ Social psychology studies have shown that during and after puberty, children become more self-conscious, more receptive and more concerned about the opinions of others. ${ }^{16}{ }^{17}$ One developmental psychology study has shown that during and after puberty, an adolescent's self-evaluation becomes more comprehensive and changes from that held previously. ${ }^{18}$ Previous studies have shown that specific groups of adolescents may be vulnerable to lower levels of self-concept than found in normal groups. For example, studies of adolescents with chronic diseases have shown that their level of self-concept is significantly lower than healthy adolescents. Adolescents with chronic diseases often feel insecure, lonely, isolated and controlled by changes resulting from chronic disease. ${ }^{19} 20$ Therefore, we suggest that chronic diseases such as AIDS will have a serious impact on the self-concept of adolescents. To date, no studies have investigated the self-concept of Chinese adolescents with HIV. In China, adolescents with HIV represent a large but specific group who have experienced multiple losses throughout their lives, thus increasing their risk of psychopathology. ${ }^{21}$ Therefore, studying the development of self-concept among adolescents with HIV, and identifying methods to help them maintain psychological well-being and healthy growth is of clear importance.

The formation and development of self-concept is influenced by many factors. It has been shown that teacherstudent relationships, peer relationships, parent-child relationships, parenting patterns, perceived stress, perceived social support and individual coping styles, are all likely to have an impact on self-concept among adolescents. ${ }^{22}$ The current study explored the factors which influence the self-concept of adolescents with HIV, focusing on both risk and protective factors, and external environment-individual internal characteristics.

A large body of research suggests that factors such as perceived stress and perceived social support in the external environment have a significant impact on the formation and development of self-concept. Perceived stress is the result of the perceptual assessment of an individual's own experience of stress resulting from specific situations or events. ${ }^{23}$ People have different perceptions about events that occur and their psychological response differs. Differences in psychological response will have different effects on mental health. In Africa, the incidence of AIDS is extremely high and adolescents are often in a high-crime and precarious environment. ${ }^{24}$ Such an environment may aggravate their sense of pressure, and thus affect their self-concept.

Social support is considered to be an important factor affecting psychological stress and physical health. From a psychological perspective, Cobb suggests that social support includes the following: emotional support; respect and support; and member attribution. ${ }^{25}$ Social support can significantly predict the emotional behaviour of adolescents, and higher social support has a protective effect on adolescent mental health. ${ }^{26}$ Researchers have shown that the relationship between social support and self-concept is stable and positively correlated. There is a difference between social support factors and the correlation between the fractal dimensions of self-concept. Social support for adolescents is primarily derived from parents, teachers, classmates and friends. Demaray et $a l^{27}$ report that the relationship between the frequency of social support and self-concept is significant. Forman $e t a l^{28}$ have shown that social support may prevent teenagers with learning disabilities (LD) from mood disorders. Adolescents with LD who receive more social support from their parents, teachers, and peers, have higher levels of self-concept than adolescents who receive less social support. ${ }^{29}$ Barroso ${ }^{30}$ concluded that social support is an important factor for adults who are long-term survivors of AIDS. Lack of social support may also cause adolescents with HIV to have lower levels of selfconcept. Cluver et $a l^{81}$ report that orphans in particular may have a lack of social support due to illness or death of family members, thereby distorting their cognitions about themselves and others.

An adolescent's self-concept is not only affected by external environmental factors, but their own internal factors. Individual coping styles and other factors have a significant impact on the emergence and development of self-concept. Coping style refers to the change in cognition and/or behaviour used by an individual in a particular stressful situation, with the aim of managing emotions and improving the problem. ${ }^{32}$ Individuals adopt specific coping styles and measures according to their own experiences after cognitive assessment of the response process. Coping style has an important impact on the status of an individual's environmental adaptation and mental health. ${ }^{33}$ At present, an important research aspect in clinical psychology is the study of the relationship between an individual's coping style, and physical and mental health. Xinyi $e t a \hat{l}^{4}$ have shown that the clarity of self-awareness or self-concept is related to more active coping behaviour. Studies of HIV-infected individuals and their coping styles suggest that a high level of active coping is positively 
related to immunisation measures, and may indirectly affect the self-concept of the AIDS patient. ${ }^{35}$

This study was designed to explore the factors which influence the self-concept of adolescents with HIV. We investigated the self-concept of adolescents with HIV, considered the environmental and individual levels and analysed the relationship between perceived stress, perceived social support, coping style and self-concept, in order to better understand the role of self-concept among adolescents with HIV. We believe this is the first study of this kind in China.

\section{METHODS}

\section{Sample size and sampling technique}

The current study was conducted in a rural county in Henan province, China, where many residents were infected with HIV through blood collection using inadequate hygiene techniques. This rural county has the highest prevalence of HIV infection in the area. We obtained village-level HIV surveillance data from the antiepidemic station in each of the counties to identify the villages with the highest number of AIDS-related deaths and confirmed HIV infections. The adolescents we surveyed were all infected by mother-tochild transmission of HIV.

A questionnaire was distributed among two groups of adolescents: 140 questionnaires were distributed in the case group (adolescents with HIV) and 139 valid questionnaires were returned (response rate of 99.3\%). Among the adolescents in the case group, there were 88 boys $(63.3 \%)$ and 51 girls $(36.7 \%)$, and the average age was $15.89 \pm 2.8$ years. The control group (healthy adolescents) was issued 150 questionnaires, and 144 valid questionnaires were returned (response rate of 96.0\%). Among the adolescents in the control group, there were 91 boys $(63.2 \%)$ and 53 girls $(36.8 \%)$, and the average age was $13.85 \pm 1.2$ years. The total number of participants in this study was therefore 283 adolescents aged $10-20$ years and of Han ethnicity. Participation of the adolescents was voluntary, and all provided informed consent.

\section{Procedure}

To recruit adolescents with HIV, we worked with the town leaders to generate lists of adolescents with confirmed diagnoses of HIV/AIDS. We approached the adolescents on the lists and invited them to participate in the study. We contacted the headmasters of local schools with the help of the Center for Disease Control and the Prevention (CDC) officer. The headmasters in each school called the adolescents with HIV together. To protect participants' privacy, the headmasters worked with adolescents to come up with an individualised plan for assessment in terms of the preferable time and place for them to feel comfortable to meet with the researchers. After the eligibility of an adolescent was confirmed, the interviewer(s) provided him/her with a detailed description of the study design, potential benefits and risks, confidentiality issues and invited him/her to participate. On the premise of ensuring no harm to the adolescents, we first obtained the informed consent of the guardian of the teenagers, and then the informed consent of the adolescents themselves. Informed written consent was sought from the adolescents and their guardians. If a child had lost both parents (ie, in the case of orphans), we obtained the informed consent from the child and his guardian.

Adolescents with HIV, from 10 to 20 (inclusive) years of age, comprised the case group. The healthy adolescents in Shangcai county who were not infected with HIV were used as the control group. Their parents were healthy and the family was complete. Inclusion criteria: age 10-20 years old; the patient meets the definition in this study of an adolescent with HIV; in the first half of the investigation, the adolescents have been living in Shangcai county. The exclusion criteria were: unconfirmed HIV infection status; the patient is too ill to participate in the study.

The interviewers were trained education and psychology graduate students. It took about 1 hour to complete the entire assessment inventory, including taking breaks. The questionnaires were collected immediately when completed. We checked the questionnaires to avoid errors and ensure data quality and provided a gift as a token of appreciation for participation. All participants signed informed consent forms after receiving explanations of the research purpose, meaning and content. All of the adolescents participated voluntarily.

\section{Patient and public involvement}

Self-concept is a cognitive assessment of one' s own abilities and weaknesses. Self-concept itself is the subjective and internal evaluation of one's self. Therefore, we selected the Piers-Harris Children's Self-concept Scale to measure their self-concept, without the influence of subjective preference on the results. We have sent the results to the local CDC in the form of email after we get the results. The CDC informs participants by phone.

\section{MEASURES}

\section{Outcome measures}

The Piers-Harris Children's Self-concept Scale is a paperand-pencil test consisting of 80 items which are scored as either true or false. The items are self-descriptive declarative statements. The scores range from 1 to 80; higher scores indicate higher levels of self-concept. The statements are worded in both positive and negative language to control for social desirability responding. The scale has good reliability and validity and the Cronbach's alpha of the scale was 0.858 in the current study.

Stress related to interpersonal stressors was assessed by the Perceived Stress Scale. The scale consists of 10 items. Each item has a score range of $0-4$, with a possible total score of 40. Higher scores indicate higher levels of stress. The internal consistency measured by Cronbach's alpha in this study was 0.847 .

The Perceived Social Support Scale consists of 12 items that were revised from three subscales (family, friend and 
other support). Participants responded to the items on a 7-point Likert-type scale indicating disagreement/agreement. Each item was divided into a total score for social support. Items were adjusted to be more appropriate for children with HIV in the current study. The items 'leaders, relatives and colleagues' were changed to 'teachers, relatives and students. Cronbach's alpha was 0.887 in this study. We used the Simplified Coping Style Questionnaire (SCSQ) to measure coping style. The SCSQ includes 20 items that contain two dimensions of coping (positive and negative). Each dimension consists of 10 items, and each item is scored on a 5-point scale, where 1 indicates 'certainly not' and 5 indicates 'certainly.' A higher score on one dimension indicates that the individual is more likely to use this type of coping strategy. The questionnaire is highly reliable and suitable for a Chinese population. The Cronbach's alpha for the two independent dimensions of coping were 0.70 and 0.69 .

\section{Data analysis}

The SPSS V.19.0 program (IBM) was used for statistical analysis. All tests were two tailed and the significance level was set at a $\mathrm{p}<0.05$. Differences between the groups were tested using Student's t-test and analysis of variance was used to test continuous variables. The relationship between environmental personality factors and adolescent self-concept was examined using Pearson correlation analyses. Hierarchical linear regression analysis was used to model the effects of environmental personality factors on self-concept in adolescents. In the regression model, gender, age, family economic status and family structure were entered in the first block to control for potential confounding variables. In the second block, perceived stress factors were entered into the model. Third, after controlling for sociodemographic variables and perceived stress factors, perceived social support was entered into the model. Finally, after controlling for sociodemographic variables, perceived stress factors and perceived social support, coping style was entered into the model.

\section{RESULTS}

\section{Study population}

Adolescents were asked to report on individual and family characteristics including age, gender, family economic status (ie, good, moderate and poor) and family structure (intact/non-intact).

\section{Comparison of self-concept between the case group and control group}

The self-concept levels of adolescents with HIV were significantly lower than healthy adolescents $(\mathrm{p}<0.05$; table 1).

\section{Sociodemographic data and self-concept total scores by different sociodemographic variables}

Of the 139 participants, 88 were males and 51 were females. The number of participants in each age group was as follows: $8-13$ years, 28 ; $13-16$ years, 80 and $16-18$
Table 1 Comparison of the levels of self-concept between HIV-infected and control adolescents

\begin{tabular}{lllll}
\hline & $\begin{array}{l}\text { Adolescents } \\
\text { with HIV } \\
(\mathbf{n}=139)\end{array}$ & $\begin{array}{l}\text { Healthy } \\
\text { adolescents } \\
(\mathbf{n}=144)\end{array}$ & $\mathbf{T}$ & P value \\
\hline $\begin{array}{l}\text { Self- } \\
\text { concept } \\
\text { score }\end{array}$ & 51.55 & 60.22 & -9.37 & $0.00^{\text {** }}$ \\
\hline
\end{tabular}

years, 31 . The family economic status was as follows: good, 48; moderate, 79 and poor, 12. Fifty-seven and eighty-two adolescents with HIV did and did not have an intact family structure, respectively. No significant differences in self-concept total scores existed between gender, age, family economic status or family structure (table 2).

Relationship between perceived stress, perceived social support, coping style factors and self-concept total scores We collected self-concept total scores for perceived stress, perceived social support and coping style factors in adolescents with HIV (table 3). Statistically significant linear relationships existed among perceived stress, perceived social support, coping style factors and the selfconcept total scores of adolescents with HIV $(p<0.05)$. Among these variables, perceived stress $(r=-0.23, p<0.05)$ and negative coping style $(\mathrm{r}=-0.26, \mathrm{p}<0.05)$ were negatively related to the self-concept total scores. Conversely, perceived social support $(\mathrm{r}=0.28, \mathrm{p}<0.05)$ and positive coping style $(\mathrm{r}=0.25, \mathrm{p}<0.05)$ were positively associated with self-concept total scores.

\section{Hierarchical linear regression analysis of the relationship among perceived stress, perceived social support, coping style factors and self-concept total scores}

Eight variables accounted for $37.0 \%$ of the total variance of the self-concept total scores (table 4). The control variables accounted for $7 \%$ of the variance in the selfconcept total scores $(\mathrm{F}$ change $=2.46)$, and among the control variables, age $(\beta=-0.19, \mathrm{t}=-2.16, \mathrm{p}=0.03)$ was significantly associated with the self-concept total scores. By including the perceived stress variable, the variance which could be explained increased to $10 \%$. The variance in self-concept total scores ( $\mathrm{F}$ change $=4.91)$ and perceived stress $(\beta=-0.19, \mathrm{t}=-2.22, \mathrm{p}=0.03)$ was significantly associated with the self-concept total scores. Adding the perceived social support factor contributed to an additional $7 \%$ of the variance in the self-concept total scores ( $\mathrm{F}$ change $=10.55$ ), and perceived social support $(\beta=0.26, t=3.25, p=0.00)$ was significantly associated with the self-concept total scores. Finally, adding the positive and negative coping factors contributed to an additional $20 \%$ of the variance in the self-concept total scores ( $\mathrm{F}$ change $=21.00)$. Positive $(\beta=0.50, \mathrm{t}=5.75$, $\mathrm{p}=0.00)$ and negative coping styles $(\beta=-0.45, \mathrm{t}=-5.33$, $\mathrm{p}=0.00$ ) were significantly associated with the selfconcept total scores. 
Table 2 Participants' sociodemographic data and selfconcept total scores by sociodemographic variables

\begin{tabular}{|c|c|c|c|c|c|}
\hline & Group & N (\%) & $\begin{array}{l}\text { Self-concept } \\
\text { score }\end{array}$ & $F / t$ & $P$ value \\
\hline \multirow[t]{3}{*}{ Gender } & & & & 0.08 & 0.78 \\
\hline & Male & $88(63.3)$ & $52.08 \pm 10.71$ & & \\
\hline & Female & $51(36.7)$ & $50.65 \pm 11.27$ & & \\
\hline \multirow[t]{4}{*}{ Age } & & & & 1.44 & 0.24 \\
\hline & $8-13$ & $28(20.1)$ & $53.43 \pm 11.86$ & & \\
\hline & $13-16$ & $80(57.6)$ & $50.21 \pm 10.67$ & & \\
\hline & $16-18$ & 31 (22.3) & $53.32 \pm 10.44$ & & \\
\hline \multirow{4}{*}{$\begin{array}{l}\text { Family } \\
\text { economic } \\
\text { status }\end{array}$} & & & & 2.74 & 0.07 \\
\hline & Good & 48 (34.5) & $50.46 \pm 10.03$ & & \\
\hline & Moderate & $79(56.8)$ & $51.18 \pm 11.38$ & & \\
\hline & Poor & $12(8.6)$ & $58.42 \pm 10.90$ & & \\
\hline \multirow{3}{*}{$\begin{array}{l}\text { Family } \\
\text { structure }\end{array}$} & & & & 0.18 & 0.67 \\
\hline & Intact & $82(59.0)$ & $52.63 \pm 10.46$ & & \\
\hline & $\begin{array}{l}\text { Non- } \\
\text { intact }\end{array}$ & $57(41.0)$ & $50.00 \pm 11.42$ & & \\
\hline
\end{tabular}

\section{DISCUSSION}

This study was the first to explore the factors which influence self-concept among adolescents in China infected with HIV. We selected a group of adolescents with HIV, and analysed the risk and protective factors. The purpose of this study was to determine whether perceived stress, perceived social support and coping style are related to the self-concept of adolescents with HIV. The overall results confirmed that age, perceived stress, perceived social support and coping style factors were associated with self-concept in adolescents with HIV. Specifically, younger age, lower perceived stress and lower levels of negative coping styles were associated with higher levels of self-concept among adolescents with HIV. Conversely, higher perceived social support and more positive coping styles were positively correlated with the self-concept of adolescents with HIV. These findings highlight the significance of these factors on the self-concept of adolescents with HIV.

Our results showed that age significantly influenced the self-concept of adolescents with HIV. Developmental psychology has shown that the children's self-concept

Table 3 Correlations among perceived stress, perceived social support, coping style factors and self-concept total scores

\begin{tabular}{lllll}
\hline & $\begin{array}{l}\text { Perceived } \\
\text { stress }\end{array}$ & $\begin{array}{l}\text { Perceived } \\
\text { social } \\
\text { support }\end{array}$ & $\begin{array}{l}\text { Positive } \\
\text { coping } \\
\text { style }\end{array}$ & $\begin{array}{l}\text { Negative } \\
\text { coping } \\
\text { style }\end{array}$ \\
\hline Self-concept & $-0.23^{\star *}$ & $0.28^{\star *}$ & $0.25^{\star *}$ & $-0.26^{\star *}$ \\
\hline
\end{tabular}

${ }^{*} p<0.05,{ }^{* *} p<0.01,{ }^{* \star *} p<0.001$. changes dramatically during adolescence and increases significantly with age. ${ }^{36}$ Our findings showed that the older the adolescents with HIV, the lower the level of selfconcept. We concluded that for this group of adolescents, with age, some drop out of school due to illness, face the fear of disease, even social pressure and discrimination Adolescents lose confidence as part of their experience of disease along with increased social stress, thus older adolescents with HIV have lower self-concept levels.

Our findings showed that perceived stress is negatively related to self-concept in adolescents with HIV. This finding was similar to related previous studies, although none of which examined the relationship between selfconcept and perceived stress of adolescents with HIV. Civitci ${ }^{37}$ and Hoffman $e t a l^{88}$ report high negative correlations between self-concept and perceived stress in adolescents. A study in China also showed that the intensity of perceived stress was significantly correlated with the level of self-concept, which was consistent with the results of our study conducted in adolescents with HIV. ${ }^{39}$ Because of the lethality of AIDS and disease-related social discrimination, people with HIV are often subject to great psychological stress. ${ }^{40}{ }^{41}$ Adolescents with HIV not only face the long-term psychological pain of losing parents, but also continue to face a variety of external stressors. These factors can lead to higher perceived stress of adolescents with HIV than that experienced by healthy adolescents, thus their self-concept tends to be lower. Therefore, in the education of families and schools with adolescents with HIV, we should teach them how to best manage and deal with stress, and how to increase their level of selfconcept. We should mainly encourage them to develop their resilience. The society should provide adolescents who have HIV with social support from a professional psychological perspective.

We found that perceived social support was positively related to self-concept among adolescents infected with HIV. The existing literature also suggests that adolescents infected with HIV who receive more perceived social support report higher levels of self-concept. A survey involving $21 \mathrm{HIV}$-positive patients in a southern US city reported that a high level of self-concept largely depends on positive social support and interactions. ${ }^{42}$ In a 5-year follow-up longitudinal study, Havik et al found that the greater the perceived social support among adolescents infected with HIV, the higher the psychological adaptation and the higher the self-concept. An international study showed that social support from teachers, classmates and parents increases the self-concept of adolescents with HIV. ${ }^{43}$ This was consistent with the findings of our study. In some areas, HIV knowledge is not adequate, and adolescents with HIV are often subjected to discrimination and indifference from others, resulting in their fear of being rejected. As a result, adolescents with HIV lose self-confidence and their sense of selfconcept suffers. Therefore, we should increase awareness of how to treat and manage AIDS patients. We should encourage adolescents with HIV to interact with others, 
Table 4 Hierarchical linear regression analysis of the relationships among perceived stress, perceived social support, coping style factors and self-concept total scores

\begin{tabular}{|c|c|c|c|c|c|c|c|}
\hline & & $\beta$ & $\mathbf{T}$ & $P$ value & F change & $\mathbf{R}^{2}$ & $\mathrm{R}^{2}$ change \\
\hline \multirow[t]{5}{*}{ Step 1} & & & & & 2.46 & 0.07 & 0.07 \\
\hline & Gender & -0.08 & -0.98 & 0.33 & & & \\
\hline & Age & -0.19 & -2.16 & 0.03 & & & \\
\hline & Family economic status & 0.10 & 1.10 & 0.27 & & & \\
\hline & Family structure & 0.11 & 1.31 & 0.19 & & & \\
\hline \multirow[t]{6}{*}{ Step 2} & & & & & 4.91 & 0.10 & 0.03 \\
\hline & Gender & -0.10 & -1.17 & 0.24 & & & \\
\hline & Age & -0.12 & -1.37 & 0.17 & & & \\
\hline & Family economic status & 0.10 & 1.19 & 0.24 & & & \\
\hline & Family structure & 0.10 & 1.14 & 0.26 & & & \\
\hline & Perceived stress & -0.19 & -2.22 & 0.03 & & & \\
\hline \multirow[t]{7}{*}{ Step 3} & & & & & 10.55 & 0.17 & 0.07 \\
\hline & Gender & -0.11 & -1.36 & 0.18 & & & \\
\hline & Age & 0.13 & -1.55 & 0.12 & & & \\
\hline & Family economic status & 0.06 & 0.73 & 0.47 & & & \\
\hline & Family structure & 0.09 & 1.16 & 0.25 & & & \\
\hline & Perceived stress & -0.18 & -2.12 & 0.04 & & & \\
\hline & Perceived social support & 0.26 & 3.25 & 0.00 & & & \\
\hline \multirow[t]{9}{*}{ Step 4} & & & & & 21.00 & 0.37 & 0.20 \\
\hline & Gender & -0.13 & -1.76 & 0.08 & & & \\
\hline & Age & -0.15 & -1.98 & 0.05 & & & \\
\hline & Family economic status & 0.05 & 0.64 & 0.52 & & & \\
\hline & Family structure & 0.07 & 0.91 & 0.36 & & & \\
\hline & Perceived stress & -0.17 & -2.20 & 0.03 & & & \\
\hline & Perceived social support & 0.15 & 2.06 & 0.04 & & & \\
\hline & Positive coping style & 0.50 & 5.75 & 0.00 & & & \\
\hline & Negative coping style & -0.45 & -5.33 & 0.00 & & & \\
\hline
\end{tabular}

enhance self-confidence and actively participate in social activities.

Correlation analyses showed that there was a significant positive correlation between self-concept, positive coping style and problem-solving among adolescents with HIV, which was negatively correlated with negative coping style, such as escape, withdrawal and inferiority. There are many studies that support our conclusion. Norcini Pala and Steca ${ }^{44}$ reported that individuals with active coping strategies acquire a high self-concept, whereas individuals with passive-avoidant coping styles will have low self-esteem. In a northern California adolescent sample, Mantzicopoulos ${ }^{45}$ found that high self-concept was correlated with active-positive coping styles. Adolescents with HIV are a specific group and they face many more pressures than healthy adolescents. Such pressures will necessitate facing problems, which may result in a negative coping style, such as escapism. The development of a long-term negative coping style is associated with a variety of psychological problems, which can affect an individual's self-evaluation and understanding. Therefore, the development of a positive or negative coping style for self-concept is very important. Adolescents with HIV should be encouraged to adopt positive and active coping strategies which will improve self-confidence, resilience and self-concept.

We identified four factors which influence the selfconcept of adolescents with HIV and discussed two aspects of the risk and protective factors, so that future work can develop a two-way intervention. Our findings suggest that we should provide more social support to adolescents with HIV so that they can cope with difficulties in a positive way and reduce their feelings of stress, which may lead to improvements in their self-concept.

\section{Study limitations}

Some limitations of this study must be acknowledged. First, the sample size of this study was small. Adolescents with HIV reside in widely dispersed areas. The survey was conducted in a county of China in Henan province where adolescents 
with HIV are relatively concentrated. Therefore, the findings of the survey can only represent the self-concept of adolescents infected with HIV, but does not represent the entire Henan province or even the entire country. Second, this study was a cross-sectional survey. After investigating the self-concept of adolescents with HIV, we also investigated the perceived stress, social support and coping styles of adolescents infected with HIV. This study only explored the relationship between adolescents with HIV and self-concept, and cannot explain the deeper causal relationship among variables; further research and analysis are warranted for validation. Third, the assessment of self-concept was carried out using the scale evaluation method, and for adolescents with HIV the differences in individual language and verbal cognitive abilities may interfere with the final findings. Fourth, the adolescents we surveyed were all infected from mother-to-child transmission. This may not be representative of the self-consciousness of all adolescents with HIV.

Contributors YY and SK conceived and designed the study, supervised the analysis and interpreted the data. $X Y$ and $X Q$ supervised the analysis, interpreted the data and wrote the preliminary manuscript. ZQ, XS and EZ supervised the data collection by JZ, WW and YC. SK performed the test administration, compiled the data and wrote the preliminary manuscript. All authors contributed to the writing and review of the manuscript and approved the final version. We wish to thank International Science Editing for their help in editing the language of the manuscript. At the same time, we would like to thank the patient advisers for their cooperation and support in this study.

Funding The authors have not declared a specific grant for this research from any funding agency in the public, commercial or not-for-profit sectors.

Competing interests None declared.

Patient consent for publication Parental/guardian consent obtained.

Ethics approval The research met ethical guidelines according to the Declaration of Helsinki, and approval was granted by the Ethics Committee of Harbin Medical University.

Provenance and peer review Not commissioned; externally peer reviewed. Data availability statement № data are available.

Open access This is an open access article distributed in accordance with the Creative Commons Attribution Non Commercial (CC BY-NC 4.0) license, which permits others to distribute, remix, adapt, build upon this work non-commercially, and license their derivative works on different terms, provided the original work is properly cited, appropriate credit is given, any changes made indicated, and the use is non-commercial. See: http://creativecommons.org/licenses/by-nc/4.0/.

\section{REFERENCES}

1 Klineberg E, Clark C, Bhui KS, et al. Social support, ethnicity and mental health in adolescents. Soc Psychiatry Psychiatr Epidemiol 2006;41:755-60.

2 Porter K, Zaba B. The empirical evidence for the impact of HIV on adult mortality in the developing world: data from serological studies. AIDS 2004;18:S9.

3 Masmas TN, Jensen $H$, da Silva $D$, et al. The social situation of motherless children in rural and urban areas of Guinea-Bissau. Soc Sci Med 2004;59:1231-9.

4 Qian H-Z, Wang N, Dong S, et al. Association of misconceptions about HIV transmission and discriminatory attitudes in rural China. AIDS Care 2007;19:1283-7.

5 Nyambedha EO, Wandibba S, Aagaard-Hansen J. Changing patterns of orphan care due to the HIV epidemic in Western Kenya. Soc Sci Med 2003;57:301-11.

6 Sengendo J, Nambi J. The psychological effect of orphanhood: a study of orphans in Rakai district. Health Transit Rev 1997;7:105-24.

7 Ntozi JP. Effect of AIDS on children: the problem of orphans in Uganda. Health Transit Rev 1997;7:23-40.
8 Minkley N, Westerholt DM, Kirchner WH. Academic self-concept of ability and cortisol reactivity. Anxiety Stress Coping 2014;27:303-16.

9 Marsh HW, Parada RH, Ayotte V. A multidimensional perspective of relations between self-concept (self description questionnaire II) and adolescent mental health (youth self-report). Psychol Assess 2004;16:27-41.

10 Gilman R, Huebner ES. Characteristics of adolescents who report very high life satisfaction. J Youth Adolesc 2006;35:293-301.

11 McCullough G, Huebner ES, Laughlin JE, et al. Life events, selfconcept, and adolescents' positive subjective well-being. Psychol Sch 2000;37:281-90.

12 Steinhausen $\mathrm{H}-\mathrm{C}$, Metzke CW. Risk, compensatory, vulnerability, and protective factors influencing mental health in adolescence. $J$ Youth Adolesc 2001;30:259-80.

13 Harter S. Causes and consequences of low self-esteem in children and adolescents. Plenum, 1993: 87-116.

14 Pich J, Bibiloni MDM, Pons A, et al. Weight self-regulation process in adolescence: the relationship between control weight attitudes, behaviors, and body weight status. Front Nutr 2015;2:14.

15 Sebastian C, Burnett S, Blakemore S-J. Development of the selfconcept during adolescence. Trends Cogn Sci 2008;12:441-6.

16 Parker JG, Rubin KH, Erath SA, et al. Peer relationships, child development, and adjustment: a developmental psychopathology perspective. John Wiley \& Sons, Inc, 1995: 96-161.

17 Vartanian LR. Revisiting the imaginary audience and personal fable constructs of adolescent egocentrism: a conceptual review. Adolescence 2000;35:639.

18 Tsai M-C, Chou Y-Y, Lin S-J. Assessment of experience and training needs in adolescent medicine: perspectives from pediatricians. Tzu Chi Medical Journal 2011;23:37-41.

19 Kaplan KM, Wadden TA. Childhood obesity and self-esteem. J Pediatr 1986;109:367-70.

20 Onyike CU, Crum RM, Lee HB, et al. Is obesity associated with major depression? results from the third National health and nutrition examination survey. Am J Epidemiol 2003;158:1139-47.

21 Manhua Zhang. Study on physical and psychological problems and the intervention of children Affectted by HIV/AIDS. Medicine and Society 2011

22 Bokhorst CL, Sumter SR, Westenberg PM. Social support from parents, friends, Classmates, and teachers in children and adolescents aged 9 to 18 years: who is perceived as most supportive? Soc Dev 2010;19:417-26.

23 Bogdan R, Pizzagalli DA. The heritability of hedonic capacity and perceived stress: a twin study evaluation of candidate depressive phenotypes. Psychol Med 2009;39:211-8.

24 Bekker L-G, Jaspan H, McIntyre J, Gray G, Bruyn GD, et al. Adolescents and HIV vaccine trials: what are the clinical trial site issues? J Int Assoc Physicians AIDS Care 2005;4:93-7.

25 Cobb S. Social support as a moderator of life stress. Psychosom Med 1976;38:300-14.

26 Martinson LE, Esposito-Smythers C, Blalock DV. The effects of parental mental health and social-emotional coping on adolescent eating disorder attitudes and behaviors. J Adolesc 2016;52:154-61.

27 Demaray MK, Malecki CK, Rueger SY, et al. The role of youth's ratings of the importance of socially supportive behaviors in the relationship between social support and self-concept. $J$ Youth Adolesc 2009;38:13-28.

28 Forman EA. The effects of social support and school placement on the Self-Concept of LD students. Learning Disability Quarterly 1988;11:115-24.

29 Al-Yagon M. Externalizing and internalizing behaviors among adolescents with learning disabilities: contribution of adolescents' attachment to mothers and negative affect. J Child Fam Stud 2014;24:1-15.

30 Barroso J. Social support and long-term survivors of AIDS. West J Nurs Res 1997;19:554-82.

31 Cluver L, Fincham DS, Seedat S. Posttraumatic stress in AIDSorphaned children exposed to high levels of trauma: the protective role of perceived social support. J Trauma Stress 2009;22:106-12.

32 Delahaij R, Van Dam K, Dam KV. Coping with acute stress in the military: the influence of coping style, coping self-efficacy and appraisal emotions. Pers Individ Dif 2017;119:13-18.

33 Firouzan V, Saghiri M, Hemmatzadeh S, et al. The assessment of mental health within health personnel and paramedical in "Tabriz Social Insurance Hospitals", Iran. Crescent J Med Biol Sci 2015.

34 Xinyi HU, Chen Y, University BJ. The Influence of Life Events on Undergraduate Students' Well-being:Chain Mediating Effect of Selfconcept Clarity and Coping Style. Chin J Health Psychol 2017.

35 Chou C-C, Chronister J, Chou C-H, et al. Responsibility Attribution of HIV infection and coping among injection drug users in Malaysia. AIDS Care 2013;25:1551-8. 
36 Smith Gabig C, Gabig CS. Phonological awareness and word recognition in reading by children with autism. Commun Disord $Q$ 2010;31:67-85.

37 Çivitci A. The Moderating role of positive and negative affect on the relationship between perceived social support and stress in college students. Educ Sci Theory Pract 2015;15:565-73.

38 Hoffman MA, Ushpiz V, Levy-Shiff R. Social support and self-esteem in adolescence. J Youth Adolesc 1988;17:307-16.

39 Lixin Yuan LZ. Effect of life events, social support, coping style and general self-efficacy on psychological health of junior middle school students. Chin J Health Psychol 2007;15:33-6.

40 Orchard TR, Druyts E, Mcinnes CW. Aids care: psychological and socio-medical aspects of AIDS/HIV. AIDS care 2010;22:324-31.
41 Au A, Chan I, Li P, et al. Stress and health-related quality of life among HIV-infected persons in Hong Kong. AIDS Behav 2004;8:119-29.

42 Lichtenstein B, Laska MK, Clair JM. Chronic sorrow in the HIVpositive patient: issues of race, gender, and social support. AIDS Patient Care STDS 2002;16:27-38.

43 Havik T, Bru E, Ertesvåg SK. School factors associated with school refusal- and truancy-related reasons for school non-attendance. Soc Psychol Educ 2015;18:221-40.

44 Norcini Pala A, Steca P. Illness perceptions and coping strategies among individuals diagnosed with HIV. J Behav Med 2015;38:620-31.

45 Mantzicopoulos P. Coping with school failure: characteristics of students employing successful and unsuccessful coping strategies. Psychol Sch 1990;27:138-43. 